\title{
Synthesis of $\mathrm{LaFeO}_{3}$ perovskite-type oxide via solid-state combustion of a cyano complex precursor: the effect of oxygen diffusion.
}

Daniel Sánchez-Rodríguez, ${ }^{1,2}$ Hiroki Wada, ${ }^{1}$ Syuhei Yamaguchi, ${ }^{1}$ Jordi Farjas, ${ }^{2}$ and HidenoriYahiro $^{1 *}$

${ }^{I}$ Department of Materials Science and Biotechnology, Graduate School of Science and Engineering, Ehime University, Matsuyama 790-8577, Japan

${ }^{2}$ GRMT, Department of Physics, University of Girona, Campus Montilivi, Edif.PII, E17071 Girona, Catalonia, Spain

*corresponding author:

Hidenori YAHIRO, Prof.

3, Bunkyo-cho, Matsuyama, Ehime, 790-8577, Japan

Phone: +81-89-927-9929 Fax: +81-89-927-9946;

E-mail: hyahiro@ehime-u.ac.jp

\section{Abstract}

The effect of oxygen diffusion on the thermal decomposition kinetics of $\mathrm{La}\left[\mathrm{Fe}(\mathrm{CN})_{6}\right] \cdot 5 \mathrm{H}_{2} \mathrm{O}$ has been explored. In particular, the critical conditions under which $\mathrm{LaFeO}_{3}$ can be synthesized via solid-state combustion of this cyano complex precursor were analytically and numerically investigated. Thermal analysis experiments as well as simulations show that the oxygen diffusion enhancement facilitates the formation of a self-propagating combustion front during the decomposition of $\mathrm{La}\left[\mathrm{Fe}(\mathrm{CN})_{6}\right] \cdot 5 \mathrm{H}_{2} \mathrm{O}$. As a consequence, the sample undergoes local overheating that raises its temperature by several hundreds of degrees. This enables the production of $\mathrm{LaFeO}_{3}$ perovskite-type oxide with a minimum contribution of external heat resources. Although the selfpropagating high-temperature method has already proven to be successful for the synthesis of perovskite-type oxides from cyano complex precursors under oxygen 
atmosphere, we will show that under the appropriate settings, air can be used instead. Moreover, the temperature of the front is related to the ease of oxygen diffusion. Therefore, the surface area and the crystal size of $\mathrm{LaFeO}_{3}$ perovskite-type powders obtained via solid state combustion have been controlled by controlling the gas flow rate at which the sample has been exposed during the treatment.

Keywords: Combustion synthesis, SHS, heteronuclearcyano complex precursor, Perovskite-type oxide

\section{Introduction}

Perovskite-type oxides, particularly the $\mathrm{LaMO}_{3}$ type, have attracted much attention in the studies of environmentally friendly catalytic systems. To date, $\mathrm{LaMO}_{3}$ perovskitetype oxides have been reported to exhibit a high catalytic activity for oxidation of hydrocarbons[1-3] and chlorinated volatile organic compounds[4] as well as for NO decomposition.[5-7] In addition, they have been widely investigated for use as electrodes[8,9] and sensing materials. [10-13] Whether aiming to produce $\mathrm{LaMO}_{3}$ perovskite-type oxide powders or to synthesize films, many diverse low-temperature chemical routes have been investigated such as molten salt synthesis, [14-18] the solgel route, [19-22] co-precipitation of hydroxides, [23-25] thermal decomposition of heteronuclearcyano metal complexes ( $\mathrm{CN}$ method), [26-32] microwave-assisted synthesis, $[30,33,34]$ solution combustion synthesis[35-37] and solid-state combustion synthesis (SSC). [21,31,38-40] Among these, we focus on the SSC using a heteronuclearcyano complex precursor. On the one hand, SSC is one of the methods with the lowest thermal budget because it takes advantage of the heat released by an exothermic reaction for the synthesis. On the other hand, heteronuclearcyano metal 
complex precursors are very convenient for the production of perovskite-type oxides due to their similar structures. [26-32]

In $\mathrm{SSC}$, the sample undergoes a thermal runaway that locally raises its temperature by several hundreds of degrees, and because this process is quasi-adiabatic, the system is kept at low temperatures. The reaction becomes self-sustained, and a combustion front propagates through the sample, transforming the precursor into the final product without requiring external heat resources. In this technique, either combustion can be induced by uniformly heating the sample or the process can be locally initiated.[41] For a low-thermal budget, special attention must be paid to this last mode, known as the self-propagating high-temperature synthesis (SHS).

Thermal analysis(TA) methods are very useful for the analysis of combustion because they allow the monitoring of the evolution of the process for a specific temperature programme and under controlled ambient conditions (pressure and atmosphere composition). [42,43] For example, using thermogravimetric analysis (TG), we showed that $\mathrm{La}\left[\mathrm{Fe}(\mathrm{CN})_{6}\right] \cdot 5 \mathrm{H}_{2} \mathrm{O}$ powder undergoes solid-state combustion provided that the sample mass is sufficiently large.[31] This allowed us to synthesize $\mathrm{LaFeO}_{3}$ perovskite-type oxide at temperatures that otherwise would be significantly higher. Since heat propagation related heat removal becomes more difficult for thicker samples,[44] above a critical thickness, the heat released by an exothermic reaction is not efficiently dissipated, and a thermal runaway takes place. Indeed, local overheating depends on the ratio between two time scales: a characteristic diffusion time related to heat propagation and a characteristic reaction time related to the heat evolved from the sample.[44-46]

$$
t_{D, c r} / t_{R, c r}=\text { const. }
$$


where the subscript $\mathrm{cr}$ stands for the system parameter values at the threshold of ignition. The Frank-Kamenetskii's solution,[45] which is probably the best known criterion for the analysis of the occurrence of a thermal runaway, establishes a critical condition that coincides with this ratio. Depending on the value of the parameter $t_{D} / t_{R}$, two regimes can be distinguished.[45,47] For $t_{R}>t_{D}$, heat is removed efficiently, and no local overheating occurs; this regime is known as the steady-state or inert solution. Conversely, when $t_{D} \gg t_{R}$, a thermal explosion prevails, and the local overheating results in a temperature rise that approaches the adiabatic temperature.

While in our previous work [31] we put the emphasis on finding a critical sample mass, in this work TA was used to investigate the critical conditions under which $\mathrm{La}\left[\mathrm{Fe}(\mathrm{CN})_{6}\right] \cdot 5 \mathrm{H}_{2} \mathrm{O}$ undergoes combustion by exploring the effect of the oxygen diffusion enhancement on the reaction time. This work will show how the kinetic parameters for the decomposition of $\mathrm{La}\left[\mathrm{Fe}(\mathrm{CN})_{6}\right]$ can be easily modified by controlling the intraparticle and interparticle oxygen diffusion. This has been explored by varying the particle size and the gas flow rate. It will be shown that as we facilitate the oxygen diffusion, the decomposition becomes faster, thus reducing the $t_{D} / t_{R}$ ratio. As a result, the experimental conditions can be optimized to successfully produce crystalline $\mathrm{LaFeO}_{3}$ perovskite-type oxide in air by the SHS method. This is a clear improvement with respect the results obtained in [31] where the SHS method could only be successfully applied under pure oxygen. In addition, calculations will be performed to support the observed results. Moreover, it is reported that overheating can be controlled through oxygen diffusion. As it is observed for the evolution of the thermal decomposition with the sample mass,[31] a range exists where the transition from the steady-state to the adiabatic regime occurs. With the transition from one regime to the other, overheating evolves from the thermalized temperature up to the adiabatic one. Therefore, accurate 
control of the oxygen diffusion in this transition allowed us to control the surface area and the crystal size of the synthesized $\mathrm{LaFeO}_{3}$ perovskite-type oxide.

\section{Experimental details}

Commercial compounds, $\mathrm{La}\left(\mathrm{NO}_{3}\right)_{3} \cdot 6 \mathrm{H}_{2} \mathrm{O}$ (Wako, 99.5\%) and $\mathrm{K}_{3}\left[\mathrm{Fe}(\mathrm{CN})_{6}\right]$ (Hayashi, 99\%), were used without further purification. $\mathrm{La}\left[\mathrm{Fe}(\mathrm{CN})_{6}\right] \cdot 5 \mathrm{H}_{2} \mathrm{O}$ was used as a precursor of perovskite-type oxide, and $\mathrm{LaFeO}_{3}$, was precipitated immediately after mixing a $1 \mathrm{M}$ aqueous solution of $\mathrm{La}\left(\mathrm{NO}_{3}\right)_{3} \cdot 6 \mathrm{H}_{2} \mathrm{O}$ and $\mathrm{K}_{3} \mathrm{Fe}(\mathrm{CN})_{6}$ at room temperature under continuous stirring (as-precipitated sample). Following the method reported by Traversa et al.,[29] the resulting precipitates were collected by suction filtration; washed with deionized water, ethanol and diethyl ether; and then finally dried in air at $50^{\circ} \mathrm{C}$.

Powders labelled M24 and M96 were obtained after ball milling using zirconia balls for 24 and 96h, respectively. The as-precipitated sample was moistened slightly with ethanol to prevent overheating during the mechanical treatment. The milling speed was set to $240 \mathrm{rpm}$.

The $\mathrm{La}\left[\mathrm{Fe}(\mathrm{CN})_{6}\right] \cdot 5 \mathrm{H}_{2} \mathrm{O}$ powders used to produce $\mathrm{LaFeO}_{3}$ perovskite-type oxides by SHS were first compressed into a pellet. A nichrome wire connected to a voltage slider was used as a combustion igniter with $10 \mathrm{~V}$ applied to it for a few seconds until a combustion front appeared on the $\mathrm{La}\left[\mathrm{Fe}(\mathrm{CN})_{6}\right] \cdot 5 \mathrm{H}_{2} \mathrm{O}$ pellet. The contact between the incandescent wire and the sample was manually controlled.

TG and differential thermal analysis (DTA) experiments were performed simultaneously using a Shimadzu DTG-60E. Powder XRD patterns were obtained using a RigakuMiniFlex II diffractometer with $\mathrm{CuK} \alpha$ radiation. SEM images were obtained with a Hitachi Miniscope TM-1000. BET analysis (Belsorp-mini, BEL JAPAN) was 
performed to determine the specific surface area by measuring the adsorptiondesorption capacity using $\mathrm{N}_{2}$ adsorbent at $-196^{\circ} \mathrm{C}$.

\section{Results and discussion}

\subsection{Kinetic analysis of the decomposition of $\mathrm{La}\left[\mathrm{Fe}(\mathrm{CN})_{6}\right] \cdot 5 \mathrm{H}_{2} \mathrm{O}$}

Figure 1 shows the curves corresponding to the evolution of the decomposition of $\mathrm{La}\left[\mathrm{Fe}(\mathrm{CN})_{6}\right] \cdot 5 \mathrm{H}_{2} \mathrm{O}$ under an oxygen atmosphere that were obtained from a dynamic TG analysis. We note that in this study relatively low heating rates were used; commonly, TG and DTA experiments are performed at temperature rates of approximately $10 \mathrm{~K} \cdot \mathrm{min}^{-1}$. The evolution of the process was explored at heating rates ranging from 0.1

to $5 \mathrm{~K} \cdot \mathrm{min}^{-1}$ in order to avoid the occurrence of thermal gradients within the sample due to the heat evolved from the reaction. These thermal gradients may quantitatively and qualitatively alter the determination of the kinetic parameters.[44] For this reason, the sample mass was limited because above a critical mass, the decomposition of $\mathrm{La}\left[\mathrm{Fe}(\mathrm{CN})_{6}\right] \cdot 5 \mathrm{H}_{2} \mathrm{O}$ accelerates due to local overheating.[31] Additionally, the value of the mass has been kept constant in consideration of the dependence exhibited by the decomposition kinetics of this precursor on the oxygen diffusion when varying the oxygen partial pressure of the surrounding gas.[32] Under these conditions, the associated TG curves exhibited a smooth mass loss step that is related to the decomposition. Such smooth evolution guarantees the absence of a thermal runaway. Otherwise, the slope of this process would be very abrupt.[31,32,48]

The kinetic methods used in thermal analysis usually consider the reaction rate as a function of the temperature and the degree of conversion.

$$
\frac{\partial \alpha}{\partial t}=k(T) \cdot f(\alpha)
$$


where $\alpha$ is the degree of transformation, $k(T)$ is the rate constant, and $f(\alpha)$ is a function related to the reaction mechanism.

The critical condition for the occurrence of combustion depends mainly on the temperature, and therefore, our analysis will be focused on the characterization of the rate constant, $\mathrm{k}(\mathrm{T})$. In thermally activated reactions, $\mathrm{k}(\mathrm{T})$ can be described by the Arrhenius relationship:[49-54]

$$
k(T)=A e^{-E_{A} / R_{G} T}
$$

where $\mathrm{A}$ is the pre-exponential factor, $\mathrm{E}_{\mathrm{A}}$ is the activation energy, and $\mathrm{R}_{\mathrm{G}}$ is the universal gas constant. As we will show in this section, diffusion is the rate-controlling process in the decomposition of $\mathrm{La}[\mathrm{Fe}(\mathrm{CN}) 6]$. For diffusion-controlled processes, the activation energy is that of the diffusivity and the pre-exponential term is inversely proportional to the square of the diffusion path, i.e., the particle radius.[55,56]

$$
A=\frac{G \cdot D}{\delta^{2}}
$$

and,

$D=D_{0} e^{-E_{A} / R_{G} T}$

Where $\mathrm{G}$ is a constant that depends on the geometry, $\mathrm{D}$ is the diffusion coefficient and $\delta$ is the radius of the particles in the case of pulverized systems.

In Figure 2, the activation energy of the curves plotted in Figure captions:

Figure 1 was determined using Friedman's isoconversional method[50,57] and a nearly constant value for any degree of transformation was obtained. This value is 
consistent with that determined from the Kissinger plot[58] $\left(\mathrm{E}_{\mathrm{A}}=85.7 \mathrm{~kJ} / \mathrm{mol}\right.$ with a correlation coefficient of 0.9993). Although these results are characteristic of a single step reaction, the overlapping of at least 2 peaks in the evolutions shown in Figure captions:

Figure 1 can be clearly observed.

To analyse this complex solid-state reaction, we have followed the procedure proposed by Perejónet al.[59] for the deconvolution of the overlapping processes. The deconvoluted peaks are shown in Figure 3. It must be highlighted that the Fraser-Suzuki function gave us a good fitting of the processes with an R-squared value higher than 0.99. From Figure 3, it is apparent that there is no a correlation between the partial area of each process and the heating rate. In addition, the Kissinger plots of the individual processes give identical activation energies (Figure 4); i.e., the reaction rates of these individual processes differ only by the pre-exponential term. Furthermore, this activation energy appears to be consistent with that obtained in the analysis of the overall decomposition process. These results suggest that the kinetics is controlled not by two different mechanisms but by a single process. Since the pre-exponential term in diffusion-controlled reactions depends on the particle size (Eq. 4), the two-peak structure could be attributed to the particle size distribution. Large particles require more time to completely react due to the longer path of the oxygen atoms diffusion. The validity of this hypothesis was first checked by direct measurement of the size of over 400 particles from an SEM imageFigure 6. The tested powder (as-precipitated powder from now on) shows particles sizes ranging from less than $1 \mu \mathrm{m}$ to as high as 60 $\mu \mathrm{m}$ (Figure 5a). The resulting particle size distribution in terms of the relative amount of particles is shown in Figure 6a, whereas Figure $6 \mathrm{~b}$ shows their relative volumes. The 
relative volume occupied by the particles has a bimodal distribution that is consistent with the two peaks observed in the DTA measurements.

Moreover, the contribution of the second DTA peak decreased significantly (Figure 7) after the presence of particles larger than $30 \mu \mathrm{m}$ was drastically reduced by manually grinding the as-precipitated powder using a mortar (Figure 5b). It must be highlighted that the samples used in this experiment have been treated at $10 \mathrm{~K} \cdot \mathrm{min}^{-1}$ so the double peak structure characteristic from the decomposition of the as-precipitated powder to be better disclosed. Therefore, it was confirmed that the enhancement of intraparticle diffusion of oxygen accelerates the decomposition of $\mathrm{La}[\mathrm{Fe}(\mathrm{CN})]_{6}$ precursor. In the following, we will see that this fact increases the possibility of undergoing a thermal runaway.

\subsection{Effect of the oxygen diffusion inside the particle}

To check that the limiting mechanism is the oxygen intraparticle diffusion we have analysed three samples composed of particles with different average sizes. Actually, a diminution of the particle size will result in an enhancement of the gas diffusion inside the particle. Conversely, a diminution of the particle size will slow down the gas exchange between pores and the surrounding atmosphere because of the reduction of the pore size. Thus, if limiting mechanism is the oxygen intraparticle diffusion, an enhancement of the reaction rate is expected when the aprticle size is reduced.

For this purpose, the as-precipitated powder was milled for 24 and $96 \mathrm{~h}$ (M24 and M96 powders, respectively). SEM images of the M24 and M96 powders are shown in Figure 5. It is evident that the particle size decreased significantly after milling for $24 \mathrm{~h}$ (Figure 5c). However, as seen from the particle suspension in water (Figure 5d), some of the largest particles still remain unbroken. Conversely, it is clear that long-term 
milling is efficient because no large particles remain in the M96 powders (Figure 5e). Additionally, using X-ray diffraction (not shown here), it has been confirmed that the precursor was not significantly decomposed after milling. Figure 8 shows a comparison between the TG curves of $5.6 \mathrm{mg}$ samples of the as-precipitated material, and the M24 and the M96 powders decomposed under oxygen atmosphere at $10 \mathrm{~K} \cdot \mathrm{min}^{-1}$. Here, we can observe a similar dependence to that observed with the sample mass[31] which is a characteristic feature of the occurrence of overheating due to the heat evolved from the reaction. Despite the lower reference temperature, the TG curve slope of the decomposition increases as the particle size is reduced. The milled powders do show the characteristic abrupt mass loss step of a thermal runaway. Therefore, both milled powders are highly overheated with respect to the furnace temperature during the decomposition process. Conversely, the smooth TG curve of the as-precipitated sample suggests that under these conditions, the overheating is not significant or, at least, is much smaller. We assume that the thermal diffusivity does not vary significantly after milling the as-precipitated powder. The same applies for the characteristic diffusion time since we kept the sample mass constant in the three experiments. Thus, a decrease in the reaction time explains the observed shift from a thermalized decomposition process to the occurrence of overheating.

To support the thermogravimetric results, calculations have been performed that simulate the spatial evolution of the temperature within the sample for the 3 different particle-sized powders when they are heated at $10 \mathrm{~K} \cdot \mathrm{min}^{-1}$. Our model takes into account heat transfer by diffusion and heat generated by an exothermic reaction as described by [48]

$\rho c \frac{\partial T}{\partial t}=\lambda \nabla^{2} T+\rho q \frac{\partial \alpha}{\partial t}$ 


$$
\frac{\partial \alpha}{\partial t}=A e^{-E_{A} / R_{G} T} f(\alpha)
$$

Here $\mathrm{q}, \lambda, \rho$ and $\mathrm{c}$ are the decomposition enthalpy, thermal conductivity, mass density and specific heat capacity of the sample, respectively, and $\alpha$ is the fraction of the transformed material ( $\alpha=0$ before decomposition, $\alpha=1$ after decomposition). For the sake of simplicity, a single-step reaction was assumed in the calculations in order to simulate the main step in the decomposition of the cyano complex precursor, i.e., the mass loss step measured at approximately $300^{\circ} \mathrm{C}$ in the thermogravimetric analysis. Thus, a sample composed of similarly sized particles was implicitly simulated. In addition, a first-order reaction model was assumed. The thermal conductivity was assumed to be very similar to that of the surrounding gas because for loose powders the effective thermal conductivity approaches that of the surrounding gas.[inclou la ref 55] $[60,61]$ The enthalpy of the reaction has been deduced by taking the maximum overheating that we measured using thermocouples as a reference, assuming that combustion is a quasi-adiabatic process.[31] It is of no use to measure the actual enthalpy of the reaction because in processes such as combustion of metalorganic materials, a significant amount of the heat released by the reaction is carried away by the volatile components so that it therefore does not contribute to the increase in the sample temperature.[62] The specific heat capacity and the particle density were measured experimentally. In addition, the presence of the crucible was taken into account by assuming the same thickness and physical properties of the crucible used in the TG experiments, i.e., made of platinum with 0.3 -mm-thick walls and an inner radius of $2.4 \mathrm{~mm}$. The results obtained in the kinetic analysis suggested that the particle size affects the reaction rate through the pre-exponential term. Therefore, this term has been varied to simulate three different particle sizes. Since kinetic analysis was performed 
only for the as-precipitated powder, the pre-exponential factor was left as a fitting parameter for the simulation of the milled powders and was obtained through trial and error. Despite the fact that this value can easily vary by several orders of magnitude for different reactions, the fitted values are within 1 order of magnitude of the measured value for the as-precipitated powder, which appears reasonable. The values of all parameters used in the simulations are summarized in Table 1 . The simulated TG curves are plotted in Figure 8 for comparison with the experimental data. Although several approximations have been assumed, the simulated TG curves are in good agreement with the experimental data and qualitatively reproduce the oxygen diffusion dependence.

Below, we present the frames showing the local temperature during the course of the decomposition for the most significant stages. Since axial symmetry for the numerical calculations has been assumed, only half of the cross-section is plotted. Examining the temperature frames, we can distinguish how a combustion front is formed in the simulated milled samples after the sudden change in the mass loss slope. Then, the front propagates through the sample until extinguishing at the latest stages of the decomposition process, so that the sample again reaches the furnace temperature. Conversely, no significant temperature gradients appeared to occur during the decomposition process of the simulated as-precipitated powder. Therefore, it is numerically confirmed that the oxygen diffusion enhancement facilitates the occurrence of combustion during the decomposition of $\mathrm{La}\left[\mathrm{Fe}(\mathrm{CN})_{6}\right] \cdot 5 \mathrm{H}_{2} \mathrm{O}$. It is also interesting to note that the overheating undergone by the sample appears to be higher for the M96 powder than that of the M24 counterpart. This means that provided the self-sustained combustion front is formed, the front temperature can be controlled in the range of 
several hundreds of degrees at the transition from the steady state to the adiabatic regime.

\subsection{Effect of the oxygen transport in the event of a thermal runaway}

So far, we have seen how the intraparticle oxygen diffusion accelerates the reaction rate, hence facilitating the occurrence of a thermal runaway. Besides, in the event of a thermal runaway the oxygen diffusivity is greatly enhanced due to the local temperature rise. Under these conditions, the oxygen consumption rate would significantly increase and one may expect that the intraparticle oxygen transport would become the limiting step. Therefore, the effect of the gas flow rate on the decomposition of the precursor is also investigated. For this purpose, the as-precipitated powder was treated in a gas flow system composed of an electric furnace and an alumina pipe. The analysis was focused on the evolution of the XRD patterns of the final products. For clarity, the measurements were carried out under an air atmosphere instead of oxygen because then, the effect is more noticeable. Figure 9 shows the XRD patterns of the as-precipitated powders $(0.4 \mathrm{~g})$ treated from room temperature to $350^{\circ} \mathrm{C}$ at $10 \mathrm{~K} \cdot \mathrm{min}^{-1}$ under different gas flow rates. Once the temperature reached $350^{\circ} \mathrm{C}$, no further power was supplied by the furnace. A gradual evolution of the degree of crystallinity is observed in the XRD patterns of the products as the interparticle oxygen trasnport is enhanced. It should be noted that when the sample was treated using just $50 \mathrm{~mL} \cdot \mathrm{min}^{-1}$ of air, no peaks attributed to the precursor or to the perovskite appeared; the product may be amorphous. As the air flow is increased up to $200 \mathrm{~mL} \cdot \mathrm{min}^{-1}$, the intensities of the main peaks attributed to the formation of crystalline $\mathrm{LaFeO}_{3}$ perovskite-type progressively grew. The presence of crystalline perovskite-type oxide at such a low furnace temperature 
indicates that a significant overheating has taken place. Additionally, the gradual evolution of the peaks suggests that overheating increases with the gas flow rate. Thus, oxygen transport through pores should be enhanced to maintain the thermal runaway.

\subsection{Synthesis of LaFeO3 perovskite-type oxides via the SHS method.}

We recently showed that the synthesis of $\mathrm{LaFeO}_{3}$ can progress under pure oxygen by using no heat resource other than the heat evolving from the sample itself.[31] This is done by keeping the system at room temperature and just locally heating the sample with a hot spot for a few seconds, i.e., by the SHS mode. In view of the results presented above, the possibility of producing $\mathrm{LaFeO}_{3}$ perovskite-type oxide by SHS is not limited to high oxygen partial pressure atmospheres. Provided good oxygen diffusion occurs, the lack of atmospheric oxygen can be compensated for. This allows the synthesis of $\mathrm{LaFeO}_{3}$ perovskite-type oxide by the SHS method under air with the production advantages that accompany this synthesis setup. In this section, we check the feasibility of using the SHS combustion mode under air by the enhancement of oxygen diffusion. In particular, we compensate the lack of oxygen with high enough gas flow rates. Several gas flow rates were tested in an attempt to control the front's temperature. On the one hand, three samples have been synthesized using the equivalent of $1.5,2.5$ and $5 \mathrm{~L} \cdot \mathrm{min}^{-1}$ of $\mathrm{CO}_{2}$ in air. A 2-cm-diameter tube conducted the air to the top of the samples locateda few centimetres from the end of the tube. The equivalent of $1.5 \mathrm{~L} \cdot \mathrm{min}$ 1 of $\mathrm{CO}_{2}$ in air appeared to be the minimum flow rate for such a configuration for the SHS mode to be applied. Thus, we can consider this as a lower limit for a combustion front that would propagate in the transition from the steady state to the adiabatic regime. The reason why gas flow rates are given in the equivalent of $\mathrm{CO}_{2}$ gas in air is because the only gas flow meter in our possession that was able to measure a high enough air flow for a self-sustained combustion front to propagate was calibrated for $\mathrm{CO}_{2}$. In 
addition, a fourth sample was synthesized using a commercial hair dryer with the expectation of reaching front temperatures close to the adiabatic regime. The hair dryer was located at approximately $10 \mathrm{~cm}$ above the sample. The synthesis process of this last sample was recorded and the more significant frames are shown in Figure 10. It can clearly be seen how a combustion front forms and progresses until the entire sample has reacted. The corresponding XRD patterns of the four products exhibit a well-defined crystalline structure consisting of apparently monophasic $\mathrm{LaFeO}_{3}$ perovskite-type oxide (Figure 11).The front propagation speed of the combustion process and surface are and crystal size of the $\mathrm{LaFeO}_{3}$ samples synthesized by the SHS method are summarized in Table 2. It is noted that the front propagation speed that establishes a clear benchmark for comparing the reaction temperatures increases with the gas flow rate. Accordingly, the crystal size increases and the specific surface area decreases. As found under the pure oxygen atmosphere,[31] the front propagates at relatively slow velocities ranging from 0.038 to $0.132 \mathrm{~mm} \cdot \mathrm{s}^{-1}$. The specific surface area and the crystal size range, respectively, from 7 to $20 \mathrm{~m}^{2} \cdot \mathrm{g}^{-1}$ and from 27 to $40 \mathrm{~nm}$. Figure 12 shows characteristic SEM images of $\mathrm{LaFeO}_{3}$ produced by SHS in air. Only the products of the sample synthesized with the assistance of a hair dryer and the sample treated with the equivalent of $1.5 \mathrm{~L} \cdot \mathrm{min}-1$ of $\mathrm{CO}_{2}$ in air are shown. The micrometric particles generated by the agglomeration of nanometric particles can be observed in both products. Since the size of the micrometric particles appears to be independent of the gas flow rate, the size and shape of the nanometric particles must be responsible for the differences in the specific surface area.

\section{Conclusions}

The kinetic parameters of the decomposition of $\mathrm{La}\left[\mathrm{Fe}(\mathrm{CN})_{6}\right]$ have been calculated. The activation energy for the decomposition was estimated to be $85.7 \mathrm{~kJ} / \mathrm{mol}$; however, 
the pre-exponential term of the reaction depends on the ease of oxygen diffusion. We have proved that the decomposition of this cyano complex compound by solid-state combustion is promoted by enhanced oxygen diffusion (either by reducing the particle size or by increasing the gas flow rate). The optimization of this last system parameter allowed us to synthesize $\mathrm{LaFeO}_{3}$ perovskite-type oxide powder by the SHS in air. Moreover, we have been able to vary the specific surface area and the crystal size of the

products obtained by this approach from 7 to $20 \mathrm{~m}^{2} \cdot \mathrm{g}^{-1}$ and from 27 to $40 \mathrm{~nm}$, respectively. This was done by accurately controlling the air flow rate at which the samples were exposed.

\section{Acknowledgements}

This work was partially funded by Japanese Society for the Promotion of Science (JSPS) with the KAKENHI Grant Number 24560948. D. S.-R. also wishes to thank the JSPS for the Postdoctoral fellowship. 
[1] M. Markova-Velichkova, T. Lazarova, V. Tumbalev, G. Ivanov, D. Kovacheva, P. Stefanov, et al., Complete oxidation of hydrocarbons on $\mathrm{YFeO}_{3}$ and $\mathrm{LaFeO}_{3}$ catalysts, Chem. Eng. J. 231 (2013) 236-244. doi:10.1016/j.cej.2013.07.029.

[2] D.W.J. Jr., P.K. Gallagher, G.K. Wertheim, E.M. Vogel, The nature and effects of platinum in perovskite catalysts, J. Catal. 48 (1977) 87-97.

doi:http://dx.doi.org/10.1016/0021-9517(77)90079-3.

[3] H. Yasuda, Y. Fujiwara, N. Mizuno, M. Misono, Oxidation of carbon monoxide on $\mathrm{LaMn}_{1-\mathrm{x}} \mathrm{Cu}_{\mathrm{x}} \mathrm{O}_{3}$ perovskite-type mixed oxides, J. Chem. Soc., Faraday Trans. 90 (1994) 1183-1189. doi:10.1039/FT9949001183.

[4] B.P. Barbero, J.A. Gamboa, L.E. Cadús, Synthesis and characterisation of $\mathrm{La}_{1-\mathrm{x}} \mathrm{Ca}_{\mathrm{x}} \mathrm{FeO}_{3}$ perovskite-type oxide catalysts for total oxidation of volatile organic compounds, Appl. Catal. B Environ. 65 (2006) 21-30.

doi:http://dx.doi.org/10.1016/j.apcatb.2005.11.018.

[5] Y. Teraoka, H. Fukuda, S. Kagawa, Catalytic Activity of Perovskite-Type Oxides for the Direct Decomposition of Nitrogen Monoxide, Chem. Lett. 19 (1990) 1-4. doi:10.1246/cl.1990.1.

[6] H. Dai, H. He, P. Li, L. Gao, C.-T. Au, The relationship of structural defectredox property-catalytic performance of perovskites and their related compounds for $\{C O\}$ and $\{N O x\}$ removal, Catal. Today. 90 (2004) 231-244. doi:http://dx.doi.org/10.1016/j.cattod.2004.04.031.

[7] Y. Teraoka, K. Nakano, W. Shangguan, S. Kagawa, Simultaneous catalytic removal of nitrogen oxides and diesel soot particulate over perovskite-related oxides, Catal. Today. 27 (1996) 107-113. doi:http://dx.doi.org/10.1016/09205861(95)00177-8.

[8] D.-K. Lim, H.-N. Im, J. Kim, S.-J. Song, Electrochemical properties of $\mathrm{LaMO}_{3}$ $(\mathrm{M}=\mathrm{Co}$ or $\mathrm{Fe})$ as the negative electrode in a hydrogen battery, J. Phys. Chem. Solids. 74 (2013) 115-120. doi:10.1016/j.jpcs.2012.08.009.

[9] S.J. Skinner, Recent advances in Perovskite-type materials for solid oxide fuel cell cathodes, Int. J. Inorg. Mater. 3 (2001) 113-121. doi:10.1016/S14666049(01)00004-6. 
[10] Z. Wang, L. Shi, F. Wu, S. Yuan, Y. Zhao, M. Zhang, Structure and humidity sensing properties of $\mathrm{La}_{1-\mathrm{x}} \mathrm{K}_{\mathrm{x}} \mathrm{Co}_{0.3} \mathrm{Fe}_{0.7} \mathrm{O}_{3}$-delta perovskite, SENSORS AND ACTUATORS B-CHEMICAL. 158 (2011) 89-96. doi:10.1016/j.snb.2011.05.046.

[11] H.-C. Cho, S. Kuramoto, S. Takase, J.-H. Song, Y. Shimizu, Sensing Properties of Impedancemetric Solid-Electrolyte NO Sensor Using Perovskite-Type Lanthanum Manganite-Based Receptor, SENSORS Mater. 24 (2012) 31-41.

[12] Y. Liu, Y. Ding, H. Gao, L. Zhang, P. Gao, B. Li, et al., $\mathrm{La}_{0.67} \mathrm{Sr}_{0.33} \mathrm{MnO}_{3}$ nanofibers for in situ, real-time, and stable high temperature oxygen sensing, RSC Adv. 2 (2012) 3872-3877. doi:10.1039/c2ra20067h.

[13] X. Sun, C. Zhang, T. Feng, D. Jiang, Sensing behavior of mixed potential $\mathrm{NO}_{2}$ sensors equipped with $\mathrm{LaMO}_{3}(\mathrm{M}=\mathrm{Fe}$ or $\mathrm{Cr})$ sensing electrodes, Ionics (Kiel). 21 (2015) 1725-1730. doi:10.1007/s11581-014-1338-2.

[14] S.K. Behera, P.K. Sahu, S.K. Pratihar, S. Bhattacharyya, Low temperature synthesis of spherical lanthanum aluminate nanoparticles, Mater. Lett. 58 (2004) 3710-3715. doi:10.1016/j.matlet.2004.07.020.

[15] T. Kojima, K. Nomura, Y. Miyazaki, K. Tanimoto, Synthesis of Various $\mathrm{LaMO}_{3}$ Perovskites in Molten Carbonates, J. Am. Ceram. Soc. 89 (2006) 3610-3616. doi:10.1111/j.1551-2916.2006.01273.x.

[16] P.K. Sahu, S.K. Behera, S.K. Pratihar, S. Bhattacharyya, Low temperature synthesis of microwave dielectric $\mathrm{LaAlO}_{3}$ nanoparticles: effect of chloride on phase evolution and morphology, Ceram. Int. 30 (2004) 1231-1235. doi:10.1016/j.ceramint.2003.12.075.

[17] C. Shivakumara, M.. Hegde, a. . Prakash, a. M.. Khadar, G.. Subbanna, N.. Lalla, Low temperature synthesis, structure and properties of alkali-doped $\mathrm{La}_{2} \mathrm{NiO}_{4}, \mathrm{LaNiO}_{3}$ and $\mathrm{LaNi}_{0.85} \mathrm{Cu}_{0.15} \mathrm{O}_{3}$ from alkali hydroxide fluxes, Solid State Sci. 5 (2003) 351-357. doi:10.1016/S1293-2558(02)00056-0.

[18] J. Yang, R. Li, J. Zhou, X. Li, Y. Zhang, Y. Long, et al., Synthesis of $\mathrm{LaMO}_{3}$ (M $=\mathrm{Fe}, \mathrm{Co}, \mathrm{Ni}$ ) using nitrate or nitrite molten salts, J. Alloys Compd. 508 (2010) 301-308. doi:10.1016/j.jallcom.2010.08.073. 
[19] Z.H. Chen, X.R. Xing, J. Dai, X.W. Huang, H.W. Li, Sol-gel synthesis of $\mathrm{LaMO}_{3}$ $(\mathrm{M}=\mathrm{Cr}, \mathrm{Mn}, \mathrm{Fe}, \mathrm{Co}, \mathrm{Ni})$ nanocrystalline powders, J. RARE EARTHS. 22 (2004) 55-57.

[20] W. Kaituo, W. Xuehang, W. Wenwei, L. Yongni, L. Sen, Synthesis of perovskite $\mathrm{LaCoO}_{3}$ by thermal decomposition of oxalates: Phase evolution and kinetics of the thermal transformation of the precursor, Ceram. Int. 40 (2014) 5997-6004. doi:10.1016/j.ceramint.2013.11.048.

[21] X. Qi, J. Zhou, Z. Yue, Z. Gui, L. Li, Short communication A simple way to prepare nanosized $\mathrm{LaFeO}_{3}$ powders at room temperature, Ceram. Int. 29 (2003) $347-349$.

[22] D. Xiaoping, Y. Changchun, Nano-Perovskite-Based $\left(\mathrm{LaMO}_{3}\right)$ Oxygen Carrier for Syngas Generation by Chemical-Looping Reforming of Methane, CHINESE J. Catal. 32 (2011) 1411-1417. doi:10.3724/SP.J.1088.2011.10416.

[23] C.-L. Kuo, Y.-H. Chang, M.-C. Wang, Crystallization kinetics of lanthanum monoaluminate $\left(\mathrm{LaAlO}_{3}\right)$ nanopowders prepared by co-precipitation process, Ceram. Int. 35 (2009) 327-332.

doi:http://dx.doi.org/10.1016/j.ceramint.2007.10.012.

[24] F.A. Fabian, P.P. Pedra, J.L.S. Filho, J.G.S. Duque, C.T. Meneses, Synthesis and characterization of $\mathrm{La}(\mathrm{Cr}, \mathrm{Fe}, \mathrm{Mn}) \mathrm{O}_{3}$ nanoparticles obtained by co-precipitation method, J. Magn. Magn. Mater. 379 (2015) 80-83. doi:http://dx.doi.org/10.1016/j.jmmm.2014.12.004.

[25] Z. Junwu, S. Xiaojie, W. Yanping, W. Xin, Y. Xujie, L. Lude, Solution-Phase Synthesis and Characterization of Perovskite $\mathrm{LaCoO}_{3}$ Nanocrystals via A CoPrecipitation Route, J. Rare Earths. 25 (2007) 601-604. doi:http://dx.doi.org/10.1016/S1002-0721(07)60570-5.

[26] Y. Matuura, S. Matsushima, M. Sakamoto, Y. Sadaoka, $\mathrm{NO}_{2}$-sensitive $\mathrm{LaFeO}_{3}$ film prepared by thermal decomposition of the heteronuclear complex, $\mathrm{La}\left[\mathrm{Fe}(\mathrm{CN})_{6}\right] \cdot 5 \mathrm{H} 2 \mathrm{O}$, J. Mater. Chem. 3 (1993) 767-769. doi:10.1039/JM9930300767.

[27] Y. Sadaoka, E. Traversa, M. Sakamoto, Preparation and Characterization of 
Heteronuclear Hexacyano Complexes, $\mathrm{Ln}_{\mathrm{x}} \mathrm{Sm}_{1-\mathrm{x}}\left[\mathrm{Co}(\mathrm{CN})_{6}\right] \cdot \mathrm{nH}_{2} \mathrm{O}(\mathrm{Ln}=\mathrm{La}, \mathrm{Er}$, and Yb), Chem. Lett. 25 (1996) 177-178. doi:10.1246/cl.1996.177.

[28] Y. Sadaoka, E. Traversa, M. Sakamoto, Preparation and structural characterization of perovskite-type $\mathrm{La}_{\mathrm{x}} \mathrm{Ln}_{1-\mathrm{x}} \mathrm{CoO}_{3}$ by the thermal decomposition of heteronuclear complexes, $\mathrm{La}_{\mathrm{x}} \mathrm{Ln}_{1-\mathrm{x}}\left|\mathrm{Co}(\mathrm{CN})_{6}\right| \cdot \mathrm{nH} 2 \mathrm{O}(\mathrm{Ln}=\mathrm{Sm}$ and Ho $), \mathrm{J}$. Alloys Compd. 240 (1996) 51-59. doi:10.1016/0925-8388(96)02300-6.

[29] E. Traversa, P. Nunziante, M. Sakamoto, Y. Sadaoka, R. Montanari, Synthesis and Structural Characterization of Trimetallic Perovskite-Type Oxides, $\mathrm{LaFe}_{\mathrm{x}} \mathrm{Co}_{1-\mathrm{x}} \mathrm{O}_{3}$, by the Thermal Decomposition of Cyano Complexes, $\mathrm{La}\left[\mathrm{Fe}_{\mathrm{x}} \mathrm{Co}_{1-\mathrm{x}}\left(\mathrm{CN}_{6}\right)\right] \cdot \mathrm{nH} 2 \mathrm{O}$, Mater. Res. Bull. 33 (1998) 673-681. doi:http://dx.doi.org/10.1016/S0025-5408(98)00044-0.

[30] S. Farhadi, S. Sepahvand, Microwave-assisted solid-state decomposition of $\mathrm{La}\left[\mathrm{Co}(\mathrm{CN})_{6}\right] \cdot 5 \mathrm{H}_{2} \mathrm{O}$ precursor: A simple and fast route for the synthesis of singlephase perovskite-type $\mathrm{LaCoO}_{3}$ nanoparticles, J. Alloys Compd. 489 (2010) 586591. doi:10.1016/j.jallcom.2009.09.117.

[31] D. Sánchez-Rodríguez, H. Wada, S. Yamaguchi, J. Farjas, H. Yahiro, Selfpropagating high-temperature synthesis of $\mathrm{LaMO}_{3}$ perovskite-type oxide using heteronuclearcyano metal complex precursors, J. Alloys Compd. 649 (2015) 1291-1299. doi:10.1016/j.jallcom.2015.07.246.

[32] S. Yamaguchi, H. Wada, D. Sánchez-Rodríguez, J. Farjas, H. Yahiro, Synthesis of perovskite-type oxide, $\mathrm{LaFeO}_{3}$, from coordination polymer precursor, $\mathrm{La}\left[\mathrm{Fe}(\mathrm{CN})_{6}\right] \cdot 5 \mathrm{H}_{2} \mathrm{O}$, J. Ceram. Soc. Japan. 124 (2016) 1-6.

[33] S.K. Nikam, D. V Dharmadhikari, A.A. Athawale, Comparative Study of Lanthanum Based Perovskites Synthesized by Different Methods, in: Giri, PK and Goswami, DK and Perumal, A (Ed.), Adv. Nanomater. Nanotechnol., 2013: pp. 33-40. doi:10.1007/978-3-642-34216-5_3.

[34] J. Prado-Gonjal, Á.M. Arévalo-López, E. Morán, Microwave-assisted synthesis: A fast and efficient route to produce $\mathrm{LaMO}_{3}(\mathrm{M}=\mathrm{Al}, \mathrm{Cr}, \mathrm{Mn}, \mathrm{Fe}, \mathrm{Co})$ perovskite materials, Mater. Res. Bull. 46 (2011) 222-230. doi:10.1016/j.materresbull.2010.11.010. 
[35] M. Kumar, S. Srikanth, B. Ravikumar, T.C.Alex, S.K. Das, Synthesis of pure and Sr-doped $\mathrm{LaGaO}_{3}, \mathrm{LaFeO}_{3}$ and $\mathrm{LaCoO}_{3}$ and $\mathrm{Sr}$,Mg-doped $\mathrm{LaGaO}_{3}$ for ITSOFC application using different wet chemical routes, Mater. Chem. Phys. 113 (2009) 803-815. doi:10.1016/j.matchemphys.2008.08.047.

[36] A.S. Prakash, A.M.A. Khadar, K.C. Patil, M.S. Hegde, Hexamethylenetetramine: A new fuel for solution combustion synthesis of complex metal oxides, J. Mater. Synth. Process. 10 (2002) 135-141. doi:10.1023/A:1021986613158.

[37] C. Zhu, A. Nobuta, I. Nakatsugawa, T. Akiyama, Solution combustion synthesis of $\mathrm{LaMO}_{3}(\mathrm{M}=\mathrm{Fe}, \mathrm{Co}, \mathrm{Mn})$ perovskite nanoparticles and the measurement of their electrocatalytic properties for air cathode, Int. J. Hydrogen Energy. 38 (2013) 13238-13248. doi:10.1016/j.ijhydene.2013.07.113.

[38] M.A. Ahmed, A.A. Azab, E.H. El-Khawas, Structural, magnetic and electrical properties of $\mathrm{Bi}$ doped $\mathrm{LaFeO}_{3}$ nano-crystals, synthesized by auto-combustion method, J. Mater. Sci. Mater. Electron. 26 (2015) 8765-8773. doi:10.1007/s10854-015-3556-4.

[39] T. Hirano, H. Purwanto, T. Watanabe, T. Akiyama, Self-propagating hightemperature synthesis of Sr-doped $\mathrm{LaMnO}_{3}$ perovskite as oxidation catalyst, J. Alloys Compd. 441 (2007) 263-266. doi:10.1016/j.jallcom.2006.09.093.

[40] T. Hirano, T. Tosho, T. Watanabe, T. Akiyama, Self-propagating hightemperature synthesis with post-heat treatment of $\mathrm{La}_{1-\mathrm{x}} \mathrm{SrxFeO}_{3}(\mathrm{x}=0-1)$ perovskite as catalyst for soot combustion, J. Alloys Compd. 470 (2009) 245249. doi:10.1016/j.jallcom.2008.02.038.

[41] S.L. González-Cortés, F.E. Imbert, Fundamentals, properties and applications of solid catalysts prepared by solution combustion synthesis (SCS), Appl. Catal. A Gen. 452 (2013) 117-131. doi:10.1016/j.apcata.2012.11.024.

[42] D. Carson, A methodological approach to the spontaneous combustion of agricultural dusts, (2014).

[43] F. Fei, D. Liang, Research progress and comparison of methods for testing self ignition materials, Procedia Eng. 11 (2011) 91-99. doi:10.1016/j.proeng.2011.04.632. 
[44] D. Sánchez-Rodríguez, H. Eloussifi, J. Farjas, P. Roura, M. Dammak, Thermal gradients in thermal analysis experiments: Criterions to prevent inaccuracies when determining sample temperature and kinetic parameters, Thermochim. Acta. 589 (2014) 37-46. doi:http://dx.doi.org/10.1016/j.tca.2014.05.001.

[45] D.A. Frank-Kamenetskii, Diffusion and Heat Exchange in Chemical Kinetics, Princeton University Press, New Jersey, 1955.

[46] A. Varma, M. Morbidelli, H. Wu, Parametric Sensitivity in Chemical Systems, Cambridge University Press, New York, 1999.

[47] J. Adler, J.W. Enig, The critical conditions in thermal explosion theory with reactant consumption, Combust. Flame. 8 (1964) 97-103. doi:10.1016/00102180(64)90035-5.

[48] D. Sanchez-Rodriguez, J. Farjas, P. Roura, S. Ricart, N. Mestres, X. Obradors, et al., Thermal Analysis for Low Temperature Synthesis of Oxide Thin Films from Chemical Solutions, J. Phys. Chem. C. 117 (2013) 20133-20138. doi:10.1021/jp4049742.

[49] M.E. Brown, M. Maciejewski, S. Vyazovkin, R. Nomen, J. Sempere, a. Burnham, et al., Computational aspects of kinetic analysis, Thermochim. Acta. 355 (2000) 125-143. doi:10.1016/S0040-6031(00)00443-3.

[50] J. Farjas, P. Roura, Isoconversional analysis of solid state transformations. A critical review. Part I. Single step transformations with constant activation energy, J. Therm. Anal. Calorim. 105 (2011) 757-766. doi:10.1007/s10973-011$1446-4$.

[51] J. Farjas, P. Roura, Isoconversional analysis of solid state transformations. A critical review. Part II. Complex transformations., J. Therm. Anal. Calorim. 105 (2011) 767-773.

[52] A. Khawam, D.R. Flanagan, Basics and applications of solid-state kinetics: a pharmaceutical perspective., J. Pharm. Sci. 95 (2006) 472-98. doi:10.1002/jps.20559.

[53] S. Vyazovkin, A.K. Burnham, J.M. Criado, L. a. Pérez-Maqueda, C. Popescu, N. 
Sbirrazzuoli, ICTAC Kinetics Committee recommendations for performing kinetic computations on thermal analysis data, Thermochim. Acta. 520 (2011) 119. doi:10.1016/j.tca.2011.03.034.

[54] S. Vyazovkin, K. Chrissafis, M.L. Di Lorenzo, N. Koga, M. Pijolat, B. Roduit, et al., ICTAC Kinetics Committee recommendations for collecting experimental thermal analysis data for kinetic computations, Thermochim. Acta. 590 (2014) 123. doi:10.1016/j.tca.2014.05.036.

[55] A.S. Mukasyan, A.S. Rogachev, Discrete reaction waves: Gasless combustion of solid powder mixtures, Prog. Energy Combust. Sci. 34 (2008) 377-416. doi:10.1016/j.pecs.2007.09.002.

[56] O.S. Rabinovich, P.S. Grinchuk, M.A. Andreev, B.B. Khina, Conditions for combustion synthesis in nanosized Ni/Al films on a substrate, Phys. B Condens. Matter. 392 (2007) 272-280. doi:10.1016/j.physb.2006.11.032.

[57] H.L. Friedman, Kinetics of thermal degradation of char-forming plastics from thermogravimetry. Application to a phenolic plastic, J. Polym. Sci. Part C Polym. Symp. 6 (1964) 183-195. doi:10.1002/polc.5070060121.

[58] H.E. Kissinger, Reaction kinetics in differential thermal analysis, Anal. Chem. 29 (1957) 1702-1706. doi:10.1021/ac60131a045.

[59] A. Perejón, P.E. Sánchez-Jiménez, J.M. Criado, L. a Pérez-Maqueda, Kinetic analysis of complex solid-state reactions. A new deconvolution procedure., J. Phys. Chem. B. 115 (2011) 1780-1791. doi:10.1021/jp110895z.

[60] Z. Klemensiewicz, Thermal Conductivity of Powders, Nature. 164 (1949) 589589.

[61] D. Sánchez-Rodríguez, J.P. López-Olmedo, J. Farjas, P. Roura, Determination of Thermal Conductivity of Powders in Different Atmospheres by Differential Scanning Calorimetry, J. Therm. Anal. Calorim. 121 (2015) 469-473. doi:10.1007/s10973-015-4429-z.

[62] E. García, D. Sánchez-Rodríguez, J.P. López-Olmedo, J. Farjas, P. Roura, The effect of volatiles on the measurement of the reaction heat by differential 
scanning calorimetry, J. Therm. Anal. Calorim. (2015) 187-194.

doi:10.1007/s10973-015-4465-8. 


\section{Figure captions:}

Figure 1 - Evolution of thermal decomposition of $\mathrm{La}\left[\mathrm{Fe}(\mathrm{CN})_{6}\right]$ powder from TG-DTA experiments performed at different heating rates.

Figure 2 - Experimental activation energy of thermal degradation of $\mathrm{La}\left[\mathrm{Fe}(\mathrm{CN})_{6}\right] \cdot 5 \mathrm{H}_{2} \mathrm{O}$ powder determined using Friedman's isoconversional method. Activation energy and pre-exponential term obtained from Kissinger plot are highlighted.

Figure 3 - Fitting of experimental curves (Circles) from Figure 1: (a) $0.1 \mathrm{~K} \cdot \mathrm{min}^{-1}$, (b) 1 $\mathrm{K} \cdot \mathrm{min}^{-1}$, (c) $2.5 \mathrm{~K} \cdot \mathrm{min}^{-1}$ and (d) $5 \mathrm{~K} \cdot \mathrm{min}^{-1}$, assuming the overlapping of two FraiserSuzuki functions. Relative contributions of each independent function to the overall process is indicated in parentheses.

Figure 4 - Kissinger plot of two overlapping processes shown in Figure 1.

Figure 5 - SEM images of as-precipitated and ground powders obtained using different magnifications. From top to bottom: (a) as-precipitated powder - x500, (b) ground powder - x500, (c) as-precipitated powder - x1200 and (d) ground powder - x1200.

Figure 6 - (a) Relative number of particles of as-precipitated powder and (b) their relative volume fraction.

Figure 7 - Comparison between characteristic DTA signals of ground and asprecipitated powders provided that samples do not undergo a thermal runaway.

Figure 8 - TG curves for decomposition of $\mathrm{La}\left[\mathrm{Fe}(\mathrm{CN})_{6}\right]$ as-precipitated, M24 and M96 powders when heated at $10 \mathrm{~K} / \mathrm{min}$ (solid line, experiments; dashed line, simulations). Below, frames showing the local temperature inside the powder at the most significant stages of the decomposition. Powder-pan interface is marked with a thin white line. 
Figure 9 - XRD patterns of products of $0.4 \mathrm{~g}$ samples of as-precipitated powder treated from room temperature to $350^{\circ} \mathrm{C}$ at $10 \mathrm{~K} \cdot \mathrm{min}^{-1}$ under air using different gas flow rates.

Figure 10 - Frames showing the front propagation in an as-precipitated $\mathrm{La}\left[\mathrm{Fe}(\mathrm{CN})_{6}\right]$ pellet that has been ignited using a nichrome wire connected to a voltage slider. (The time since the front is set is indicated for each frame.)

Figure 11 - XRD patterns of $\mathrm{LaFeO} 3$ perovskite-type oxide produced by the SHS method using different air flow rates.

Figure 12 - SEM micrographs of $\mathrm{LaFeO}_{3}$ produced by SHS for the sample synthesized with assistance from a hair dryer using $10 \mathrm{k}$ (a) and 20k (b) magnification. Below, the counterpart SEM micrographs of the sample treated with the equivalent of $1.5 \mathrm{~L} \cdot \mathrm{min}-1$ of $\mathrm{CO}_{2}$ in air $(\mathrm{c}, \mathrm{d})$. 
Table 1. Physical parameters of $\mathrm{La}\left[\mathrm{Fe}(\mathrm{CN})_{6}\right] \cdot 5 \mathrm{H}_{2} \mathrm{O}$ powder used in the simulations.

\begin{tabular}{lr}
\hline & $\mathrm{La}\left[\mathrm{Fe}(\mathrm{CN})_{6}\right] \cdot 5 \mathrm{H}_{2} \mathrm{O}$ \\
\hline Thermal conductivity, $\lambda, \mathrm{W} /(\mathrm{m} \cdot \mathrm{K})$ & 0.05 \\
Specific heat capacity, $c, \mathrm{~J} /(\mathrm{kg} \cdot \mathrm{K})$ & 1892 \\
Density, $\rho, \mathrm{kg} / \mathrm{m}^{3}$ & 2207 \\
Specific heat of reaction, $q, \mathrm{~J} / \mathrm{kg}$ & $1.5 \times 10^{6}$ \\
Activation energy, $E_{A}, \mathrm{~J} / \mathrm{mol}$ & $85.7 \times 10^{5}$ \\
\hline
\end{tabular}

Table 2. Front propagation speed of combustion process and surface area and crystal size of the $\mathrm{LaFeO}_{3}$ samples synthesized by SHS method using different gas flow rates.

\begin{tabular}{lrrr}
\hline & Front propagation speed & Surface area & Cristal size \\
\hline $1.5 \mathrm{~L} \cdot \mathrm{min}^{-1}$ & 0.038 & 20.19 & 26.83 \\
$2.5 \mathrm{~L} \cdot \mathrm{min}^{-1}$ & 0.043 & 15.33 & 28.85 \\
$5 \mathrm{~L} \cdot \mathrm{min}^{-1}$ & 0.048 & 13.68 & 31.30 \\
& & & 39.45 \\
\hline
\end{tabular}




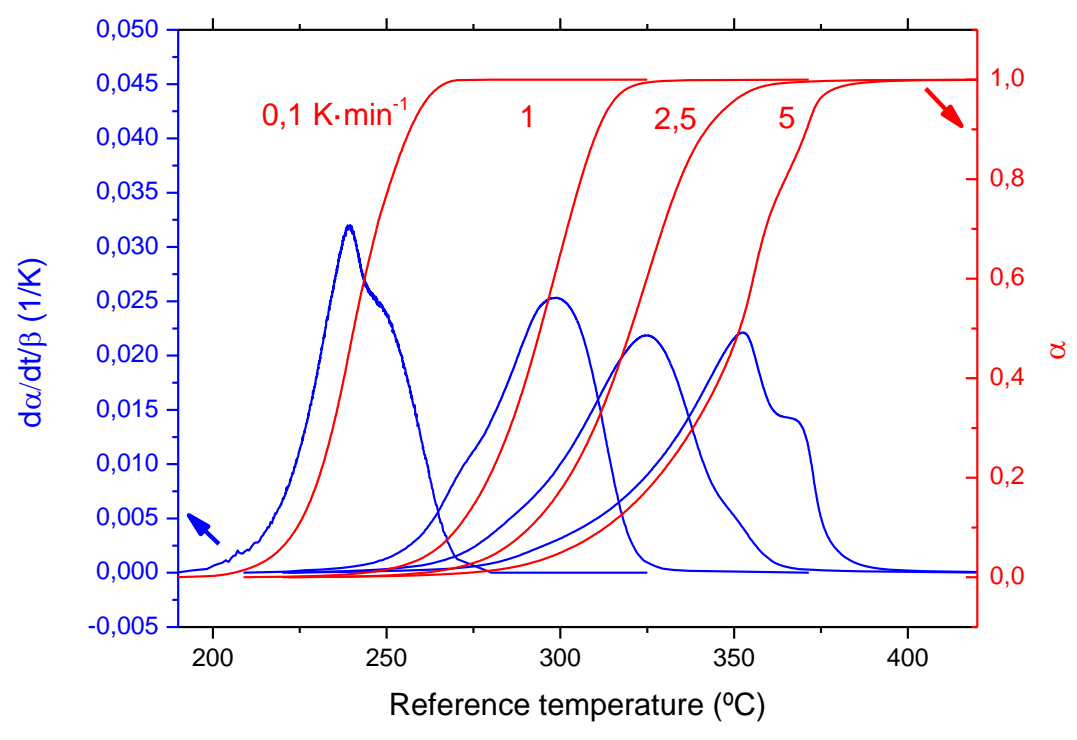

Figure 1 - Evolution of thermal decomposition of $\mathrm{La}\left[\mathrm{Fe}(\mathrm{CN})_{6}\right]$ powder from TGDTA experiments performed at different heating rates. 


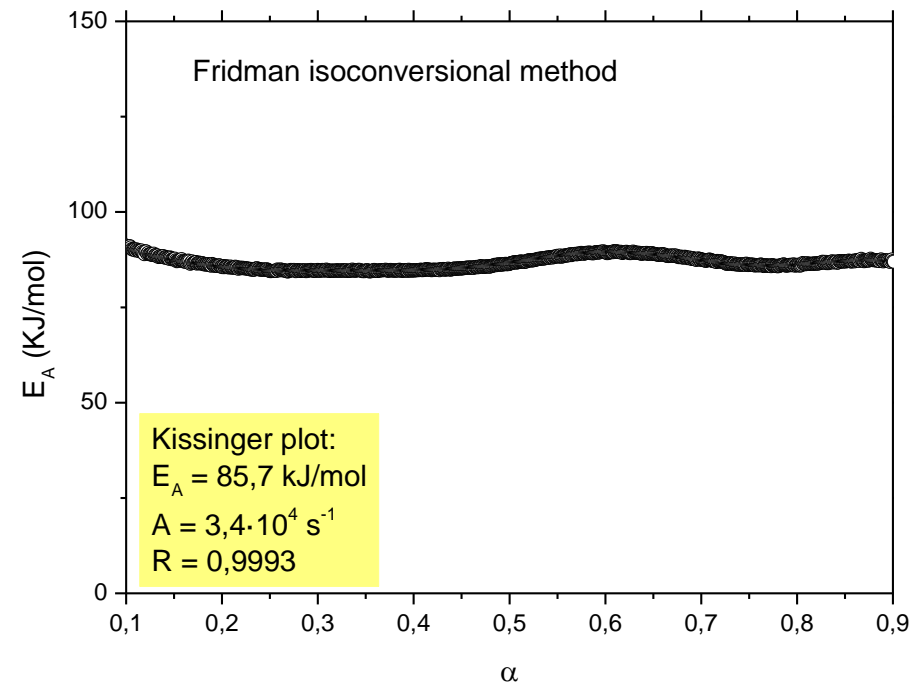

Figure 2 - Experimental activation energy of thermal degradation of $\mathrm{La}\left[\mathrm{Fe}(\mathrm{CN})_{6}\right] \cdot 5 \mathrm{H}_{2} \mathrm{O}$ powder determined using Friedman's isoconversional method. Activation energy and pre-exponential term obtained from Kissinger plot are highlighted. 

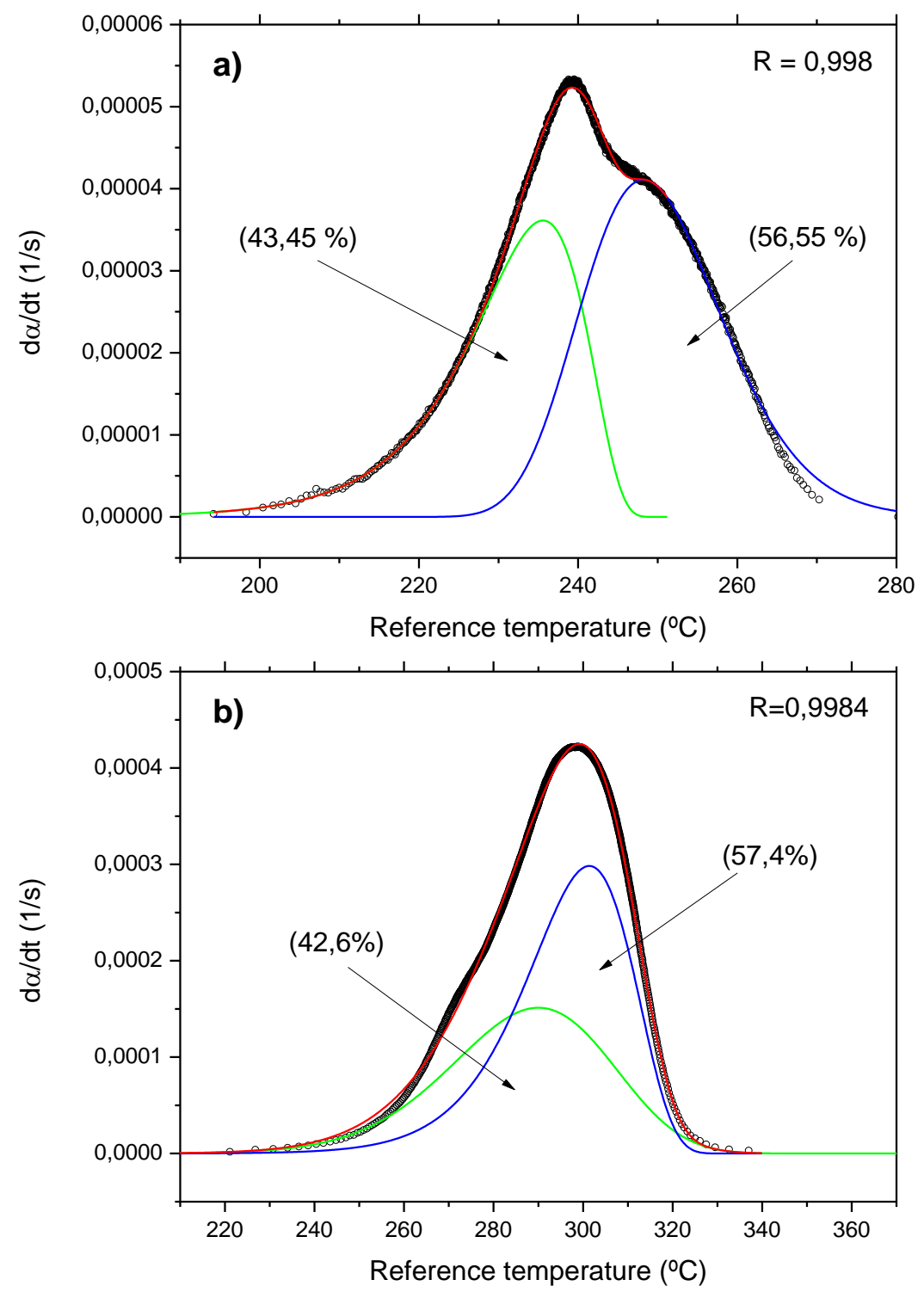

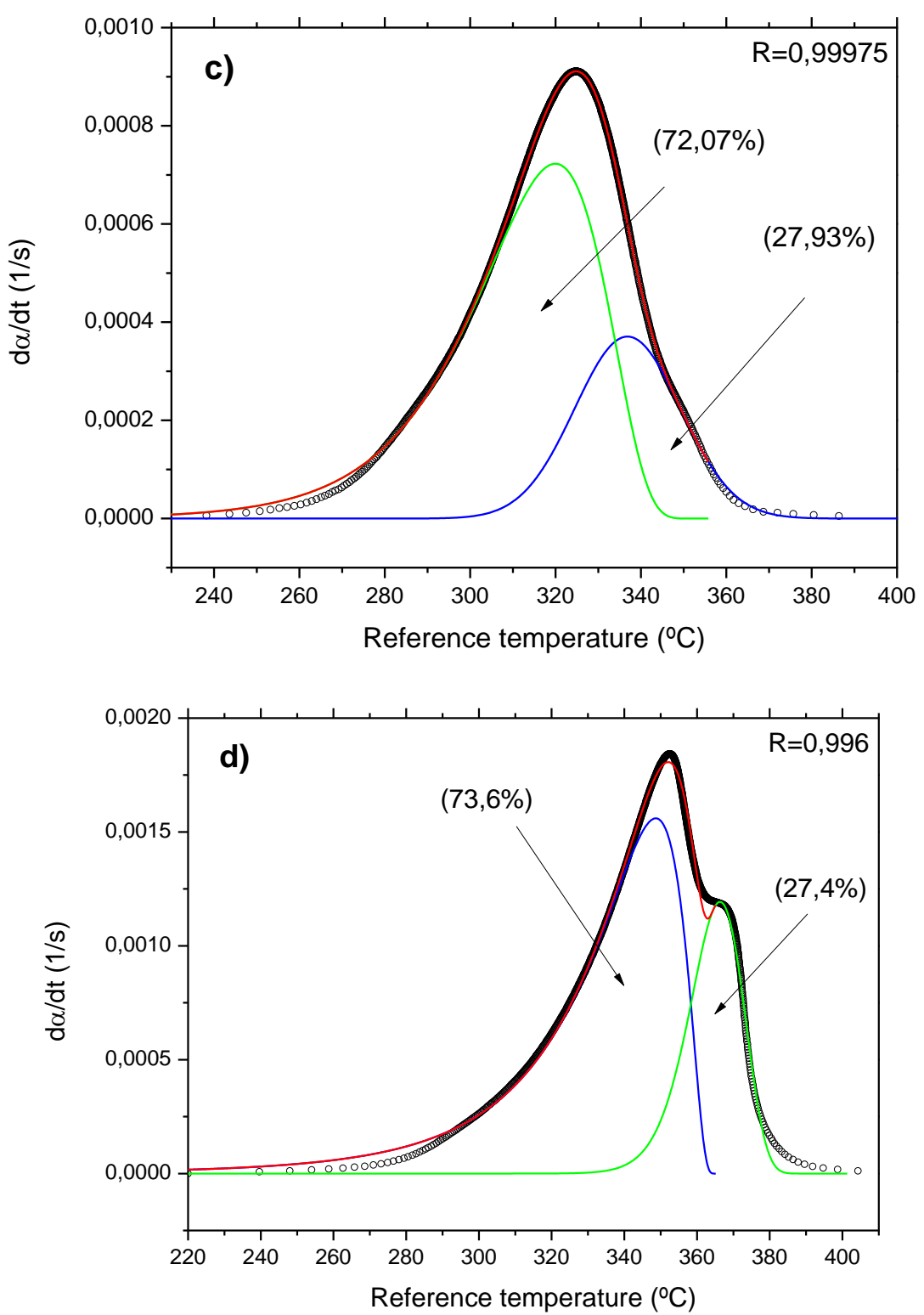

Figure 3 - Fitting of experimental curves (Circles) from Figure 1: (a) $0.1 \mathrm{~K} \cdot \mathrm{min}^{-1}$, (b) $1 \mathrm{~K} \cdot \mathrm{min}^{-1}$, (c) $2.5 \mathrm{~K} \cdot \mathrm{min}^{-1}$ and (d) $5 \mathrm{~K} \cdot \mathrm{min}^{-1}$, assuming the overlapping of two Fraiser-Suzuki functions. Relative contributions of each independent function to the overall process is indicated in parentheses. 


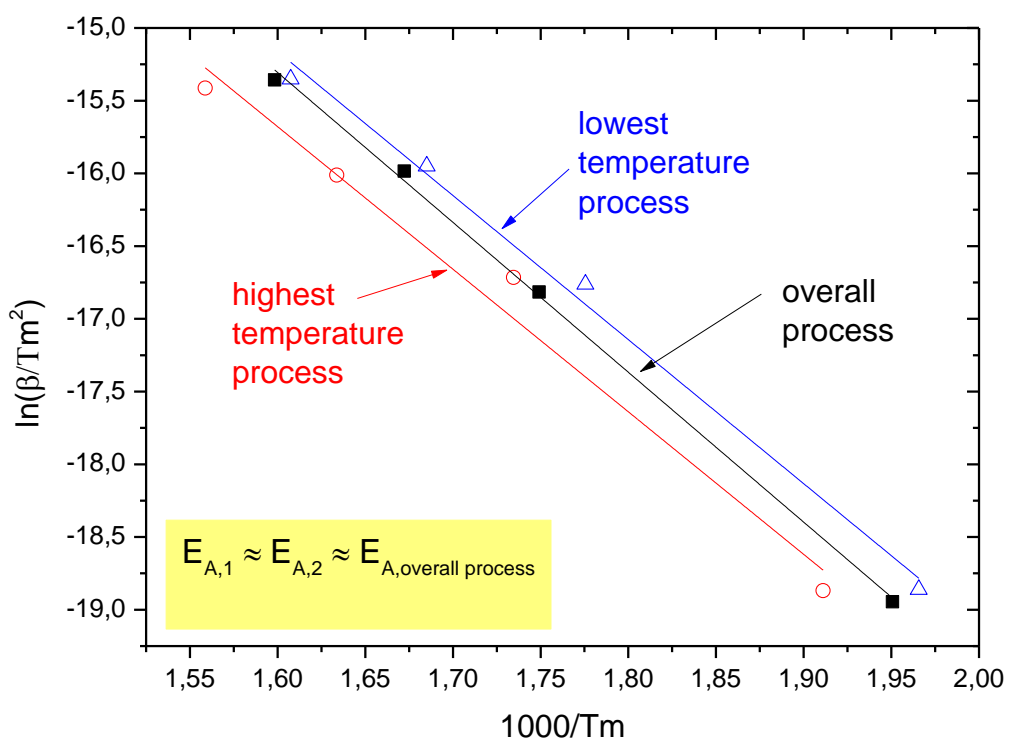

Figure 4 - Kissinger plot of two overlapping processes shown in Figure 1. 

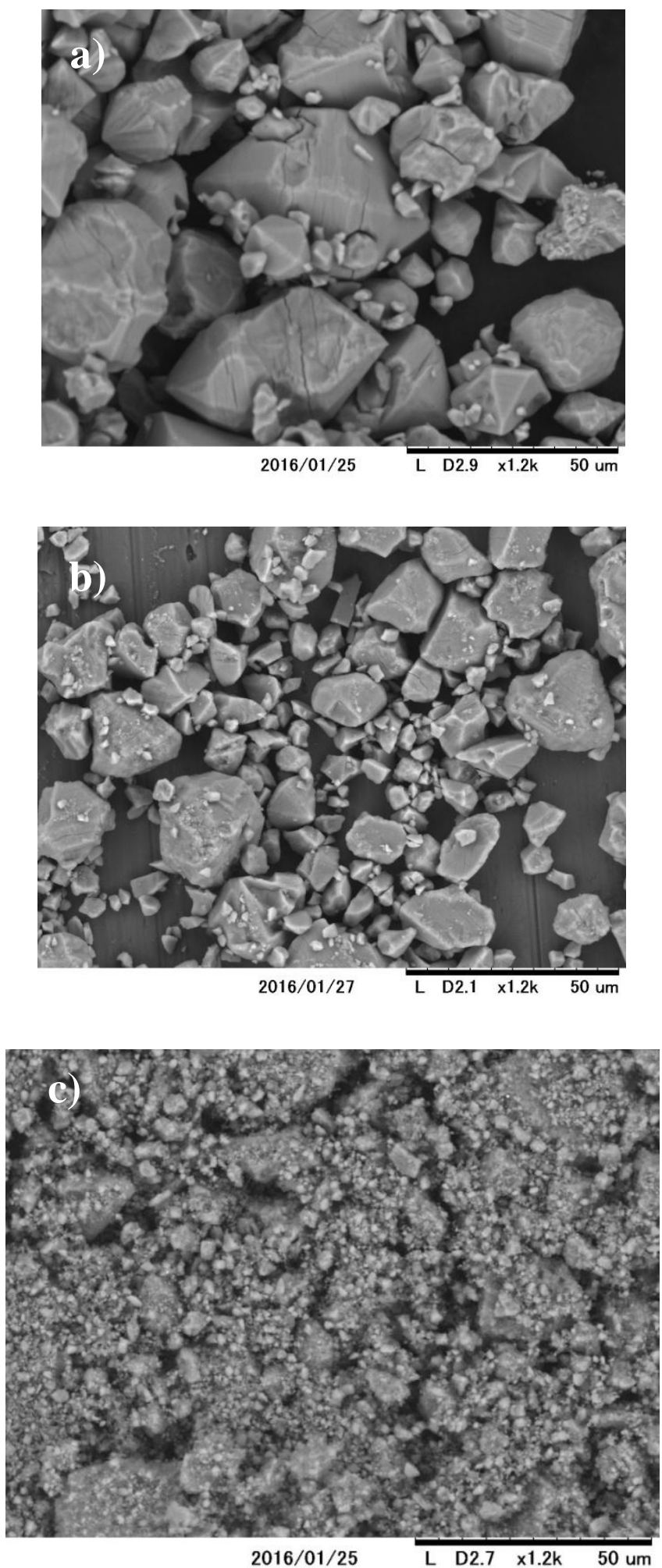

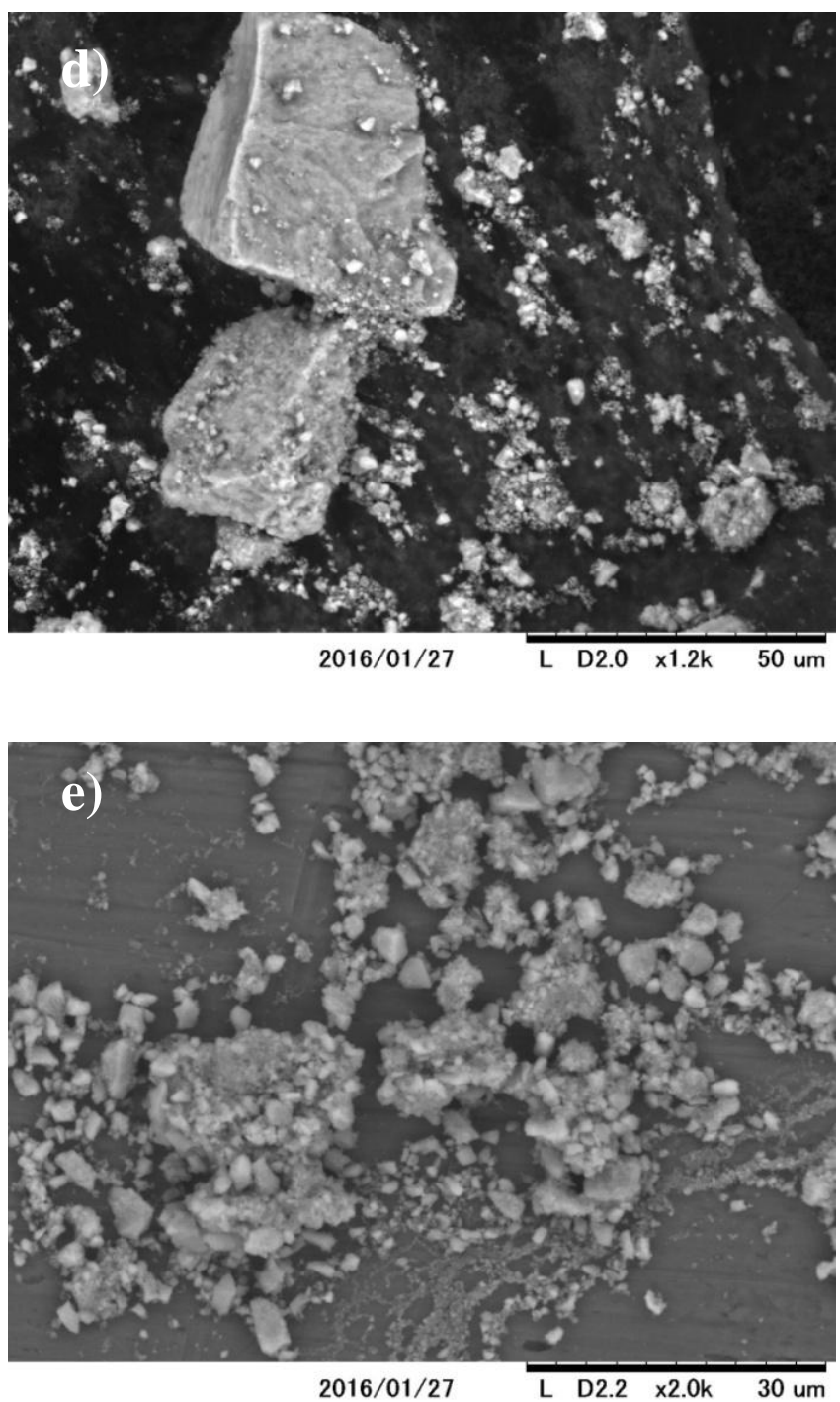

Figure 5 - SEM images of as-precipitated and ground powders obtained using different magnifications. From top to bottom: (a) as-precipitated powder - x500, (b) ground powder - x500, (c) as-precipitated powder - x1200 and (d) ground powder - x1200. 

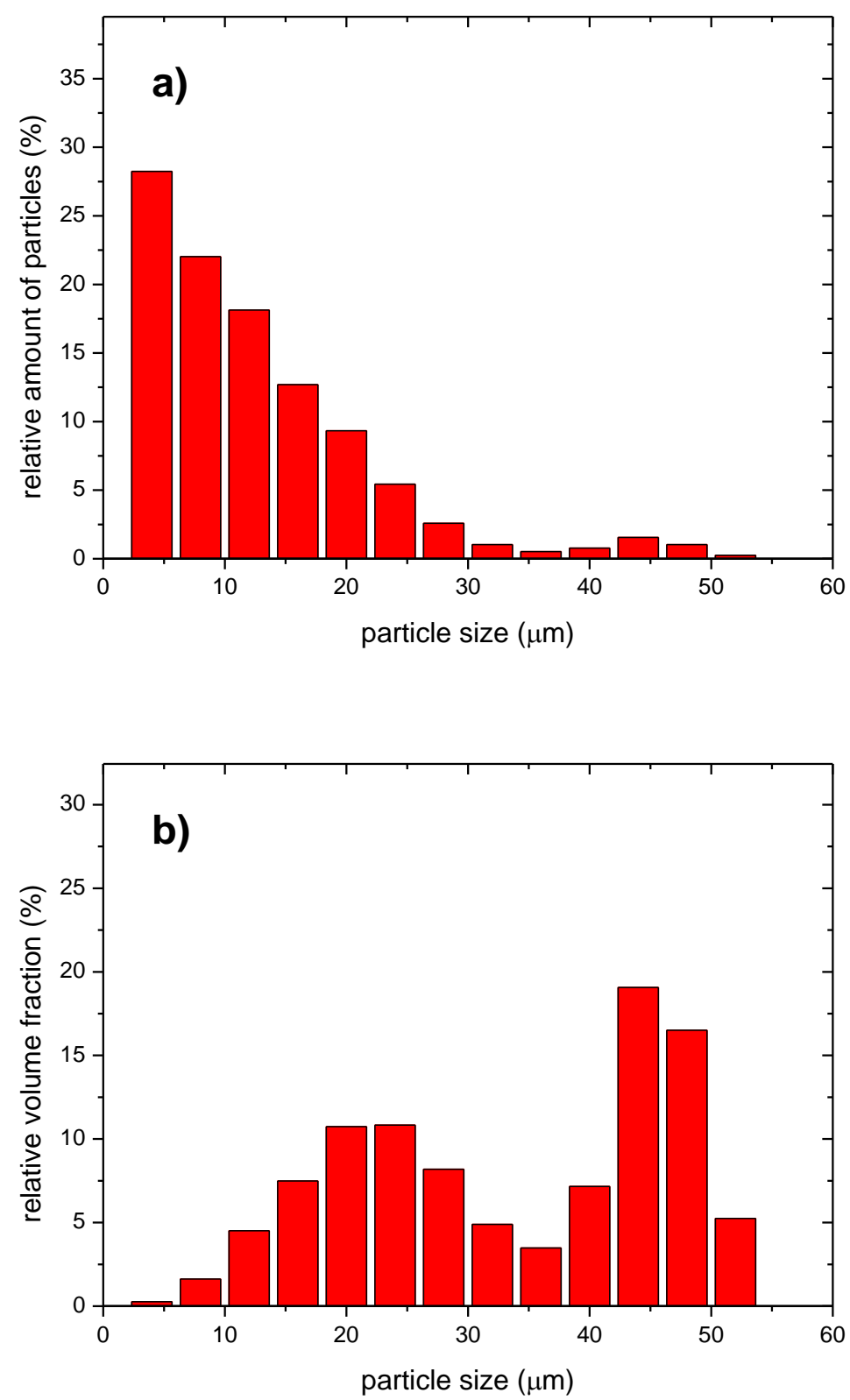

Figure 6- (a) Relative number of particles of as-precipitated powder and (b) their relative volume fraction. 


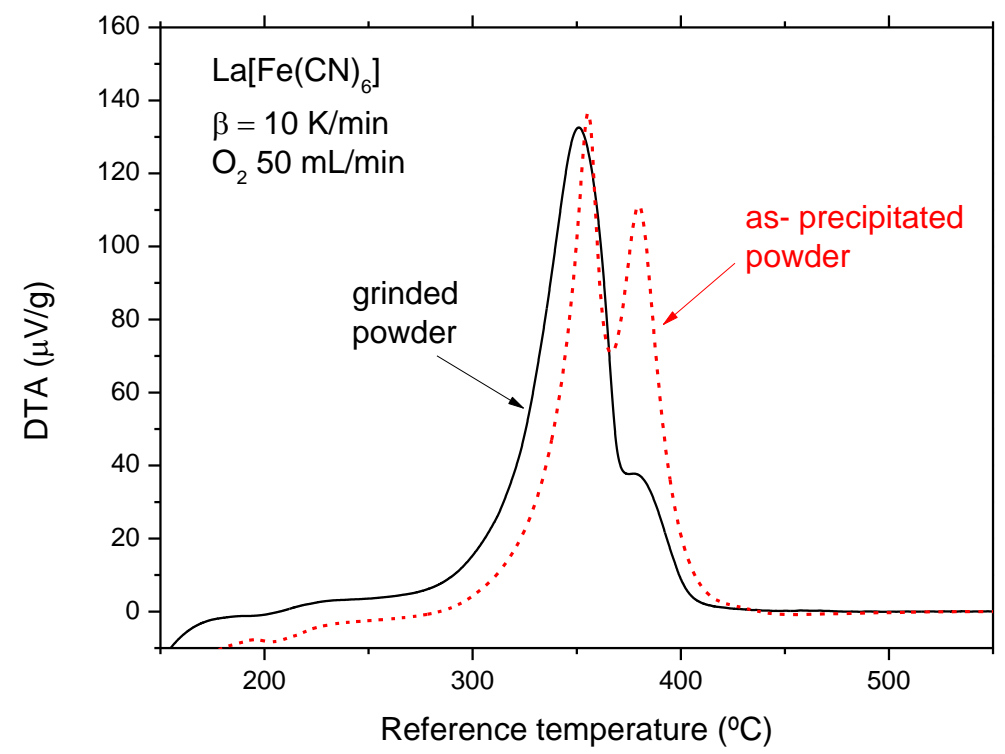

Figure 7 - Comparison between characteristic DTA signals of ground and asprecipitated powders provided that samples do not undergo a thermal runaway. 

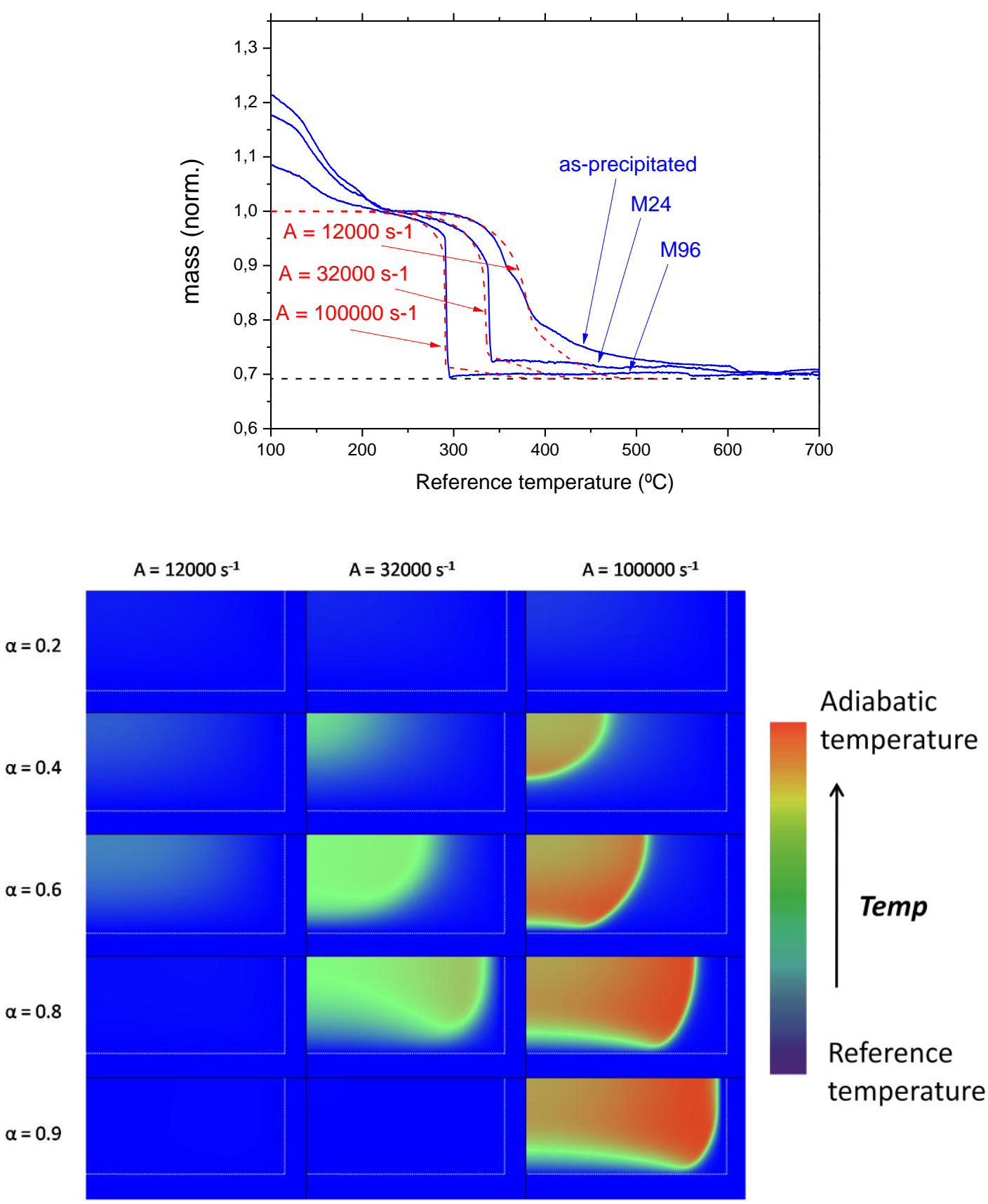

Figure 8 - TG curves for decomposition of $\mathrm{La}\left[\mathrm{Fe}(\mathrm{CN})_{6}\right]$ as-precipitated, $\mathrm{M} 24$ and M96 powders when heated at $10 \mathrm{~K} / \mathrm{min}$ (solid line, experiments; dashed line, simulations). Below, frames showing the local temperature inside the powder at the most significant stages of the decomposition. Powder-pan interface is marked with a thin white line. 


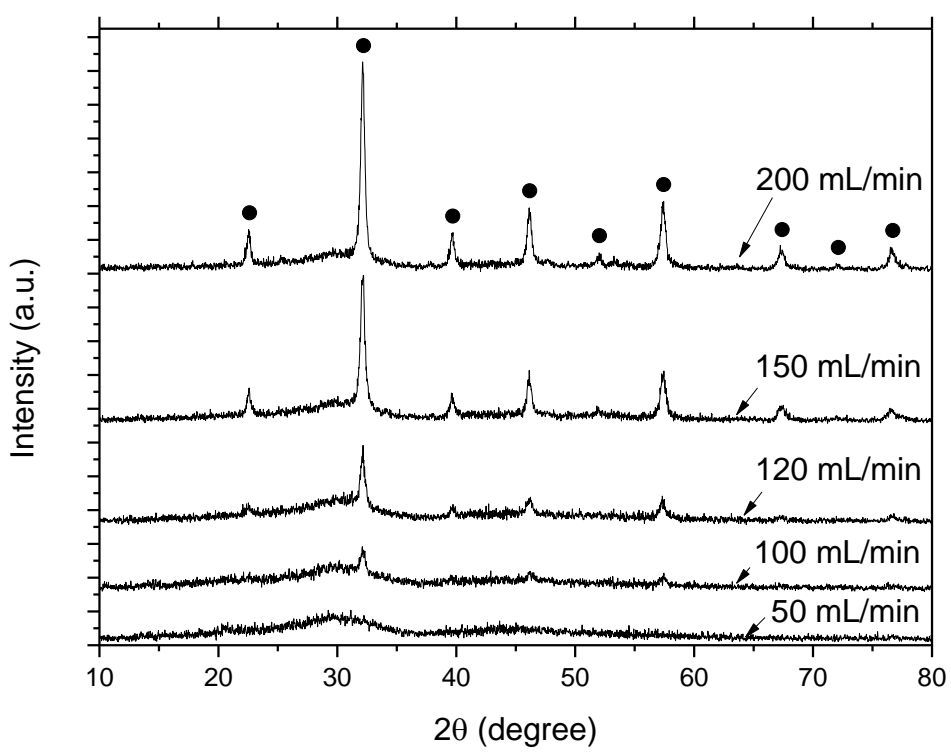

Figure 9 - XRD patterns of products of $0.4 \mathrm{~g}$ samples of as-precipitated powder treated from room temperature to $350^{\circ} \mathrm{C}$ at $10 \mathrm{~K} \cdot \mathrm{min}^{-1}$ under air using different gas flow rates. 


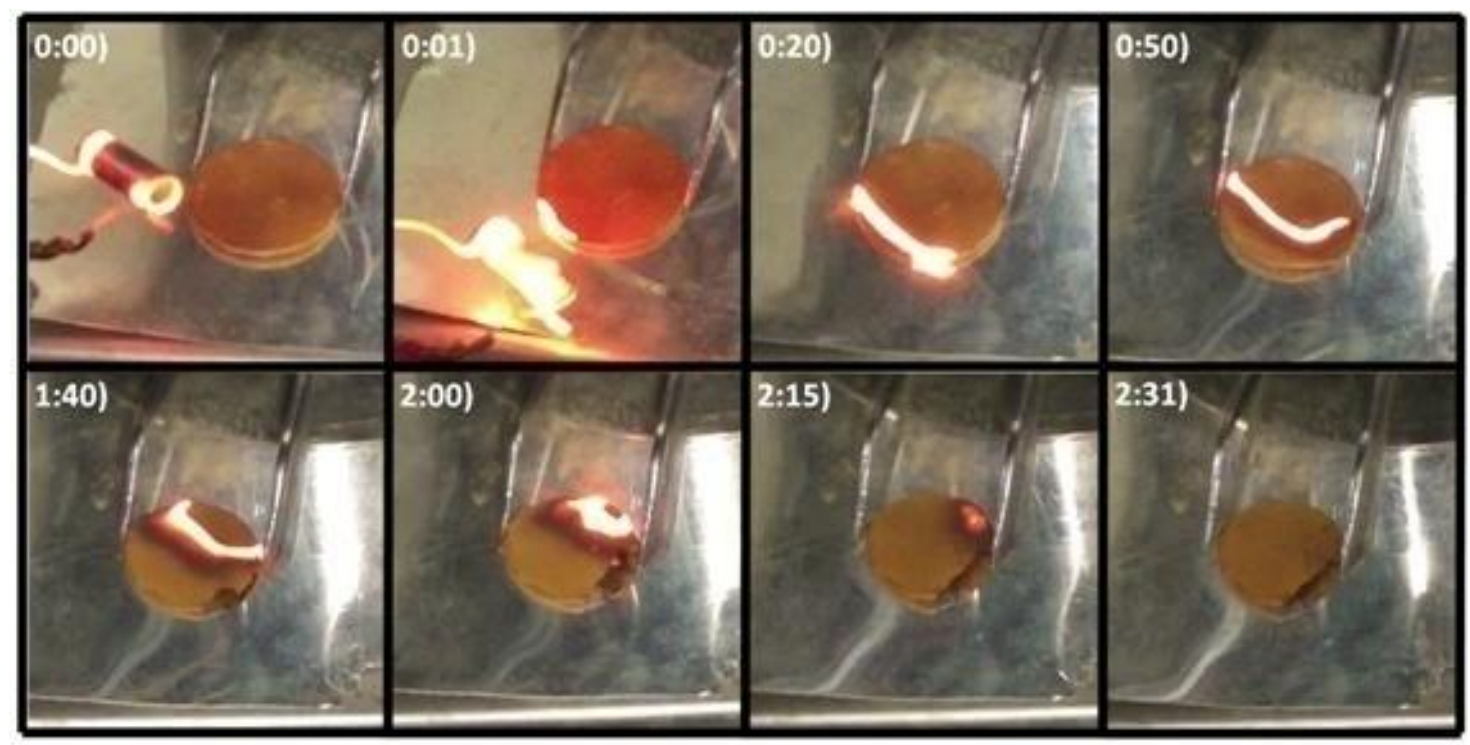

Figure 10 - Frames showing the front propagation in an as-precipitated $\mathrm{La}\left[\mathrm{Fe}(\mathrm{CN})_{6}\right]$ pellet that has been ignited using a nichrome wire connected to a voltage slider. (The time since the front is set is indicated for each frame.) 


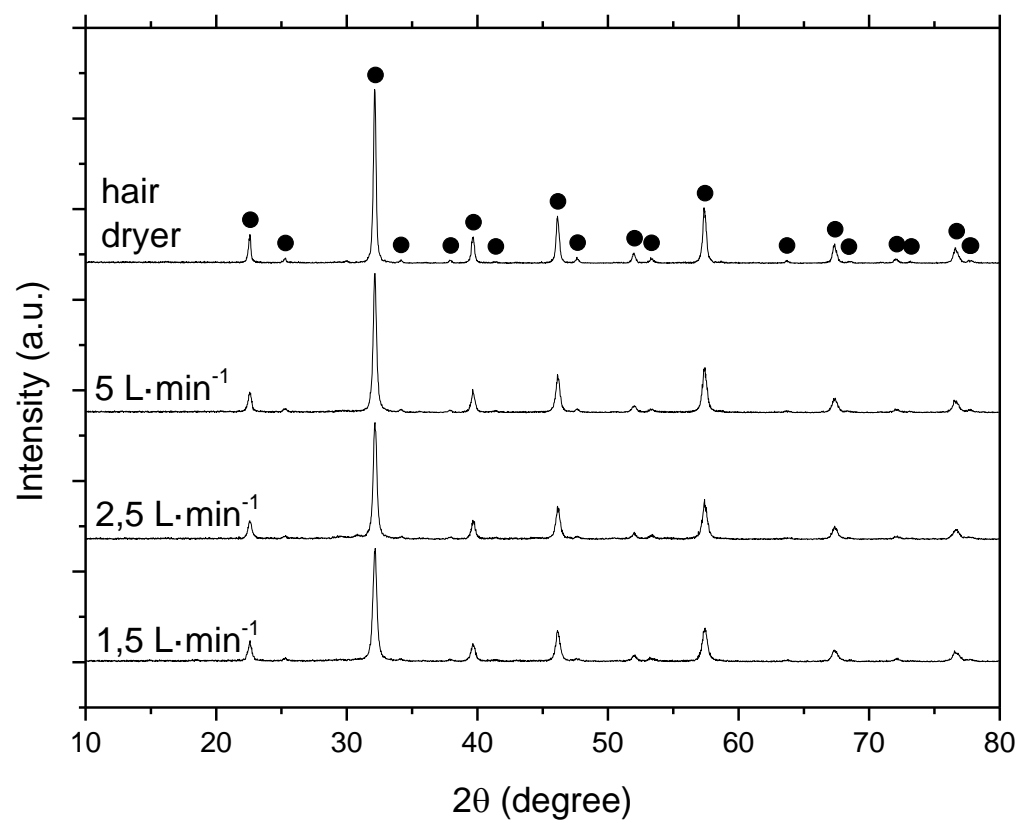

Figure 11 - XRD patterns of $\mathrm{LaFeO3}$ perovskite-type oxide produced by the SHS method using different air flow rates. 

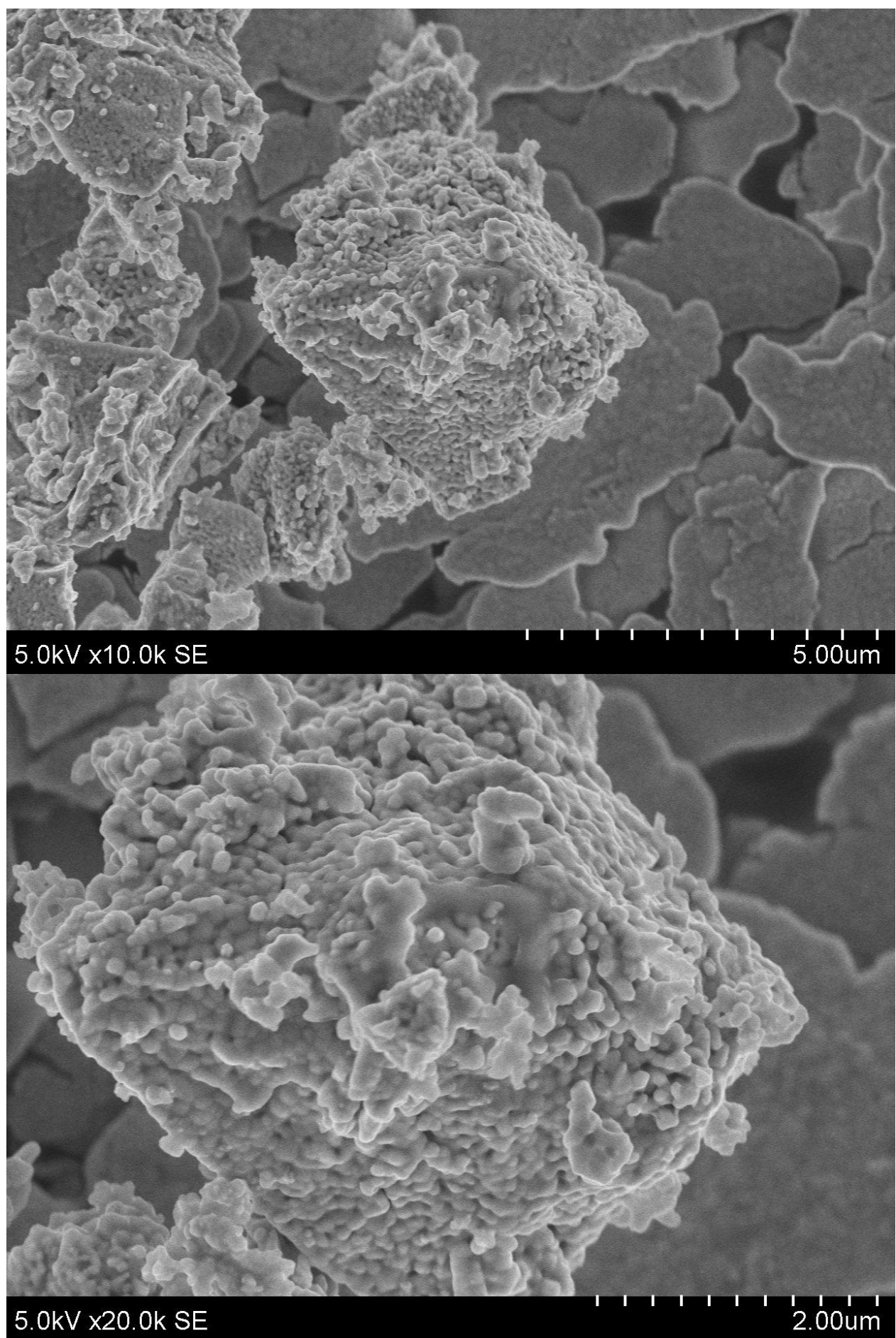

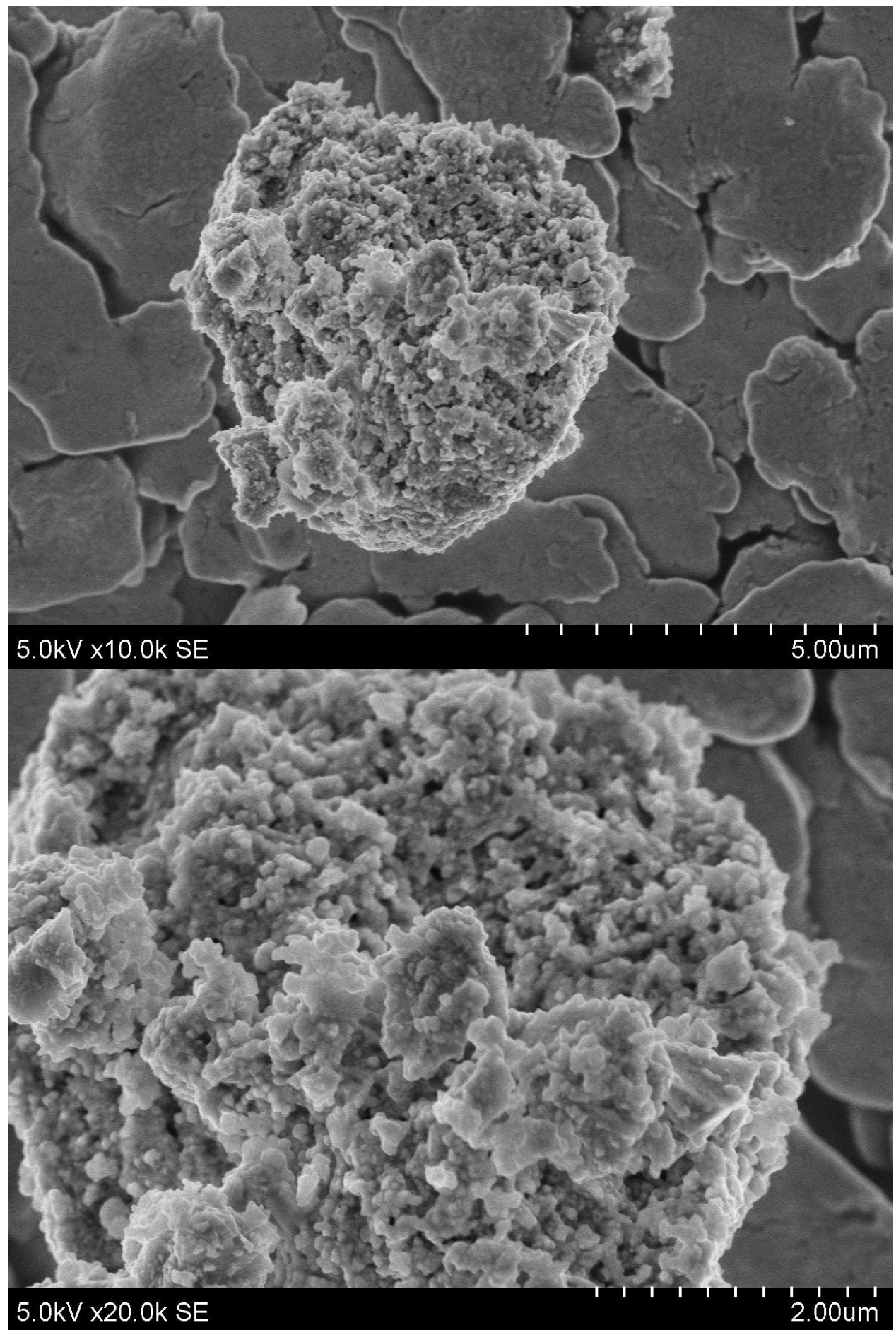

Figure 12- SEM micrographs of $\mathrm{LaFeO}_{3}$ produced by SHS for the sample synthesized with assistance from a hair dryer using $10 \mathrm{k}$ (a) and $20 \mathrm{k}$ (b) magnification. Below, the counterpart SEM micrographs of the sample treated with the equivalent of $1.5 \mathrm{~L} \cdot \mathrm{min}-1$ of $\mathrm{CO}_{2}$ in air $(\mathrm{c}, \mathrm{d})$. 